\title{
Influence of Native Language Transfer on Senior High School English Writing
}

\author{
Yuhang Yuan \\ University of Shanghai for Science and Technology, China
}

\begin{abstract}
English writing is one of the important ways to show the comprehensive ability of second language. The native language transfer has long been concerned by language learners since it was proposed. This study adopts qualitative and quantitative research methods to explore the influence of mother tongue transfer on senior high school students' English writing and puts forward corresponding teaching strategies. Through the research, it can be found that native language transfer errors account for a large proportion of errors in English writing error types. In addition, native language transfer has a significant influence on students' English writing level. It is helpful for students to improve their second language writing ability by adopting comprehensible input and other teaching methods related to mother tongue transfer.
\end{abstract}

Index Terms-English writing, second language, native language transfer, comprehensible input

\section{INTRODUCTION}

Language transfer has always been an important research topic in the field of second language acquisition and applied linguistics, especially about the native language transfer. Writing can show people's thinking and comprehensive ability well. English writing has always been an indispensable part of English examination, which is closely related to many factors. Most of the students in the primary stage of English writing often rely on the cultural habits and thinking mode of their mother tongue, resulting in the positive and negative transfer of mother tongue in the process of second language learning. Native language and the target language represent two cultures and many previous factors, which will affect the accurate expression of the target language from time to time. In communication, when there is no suitable word to express, people will consciously or unconsciously apply the limited target language rules or forms that have learned to the new language phenomenon, or "borrow" the words in their mother tongue that have the same meaning or function as a substitute, and assume that this form of substitution can continue their communication activities. In the past, many scholars have studied the role of mother tongue in the process of second language learning, especially in English writing. There are different opinions in previous studies, such as the positive or negative influence of native language on the second language level, or the mother tongue has nothing to do with the second language level. However, the overall research is not systematic nor specific, and there is less attention on the role and specific performance of mother tongue transfer in different stages of second language learning. Combining with qualitative and quantitative research methods, this article aims to explore the specific manifestations of mother tongue transfer in senior high school students' English writing by consulting, sorting and analyzing the literature, and then to explore effective English writing learning strategies, which will help domestic students improve their English writing level by using mother tongue transfer ability, which is of great importance to the acquisition of different languages.

\section{LITERATURE REVIEW}

This article first expounds the research trend of second language writing and the concept and connotation of mother tongue transfer, and comprehensively combs the research status and trends at home and abroad.

\section{A. Literature Review of Second-language Writing}

The problems in English writing and teaching methods have been the concern of scholars and the public from ancient times to the present. Foreign scholars first studied their mother tongue writing, and then gradually extended to second language writing. Lay paid attention to the problem of native language thinking and second language thinking conversion in the process of second language writing, which draws people's attention (Lay, 1982).

Wang Wenyu and Wang lifei (2004) summarized and reviewed the mother tongue thinking phenomenon, discourse characteristics, factors affecting writing and L2 testing in L2 writing. At the same time, they found the characteristics of L2 writing and discussed the L2 marking mechanism. Through collecting a variety of core journals in the past 10 years and adopting coding and quantitative research methods, Chang chang and Chang haichao (2020) pointed out that scholars had paid much attention to the theory and teaching methods of second language writing in recent years. The research focuses on the combination of subject and object, and most of them are empirical research, but the comprehensive degree is not enough. 
The phenomenon of language transfer has been concerned by scholars from the last century. As for the definition of language transfer, many scholars have spoken out their opinions about this. Krashen (1983) vividly described the phenomenon of transfer. He believed that transfer was a phenomenon in which learners resorted to mother tongue knowledge in the process of communication due to the lacking of relevant target language knowledge in the process of foreign language acquisition. Besides, Odlin (1989) held the view that language transfer meant the influence due to the similarities and differences between target language and other language people had commanded. Therefore, we can say that language transfer refers to the phenomenon that learners consciously or unconsciously use native language rules to process the target language information because they are not familiar with the grammar rules of the target language. Positive transfer will facilitate the transfer of language learning, that is, using mother tongue correctly can effectively promote the learning of the target language. While negative transfer will hinder the development of second language. Dai Weidong (2002), a domestic scholar, had studied the issue of language transfer and discussed four core issues (definition, comparison, prediction and generalization). He believed that the development of language transfer had roughly gone through three stages: in the 1950s and 1960s, language transfer was connected with the dominant behaviorism linguistic theory at that time. The language transfer was influenced by Chomsky in the next decade. Many linguists objected to some theories related to language transfer. Since the 1970s and 1980s, people began to explore the role of transfer in foreign language learning from the psychological, cognitive and social perspectives.

\section{Literature Review of Influence of Native Language Transfer on English Writing}

Since the 21st century, many scholars have linked the transfer of native language with the study of second language writing. Wang Lifei and Wen Qiufang (2004) used linear structural equation modeling software to describe the path map of mother tongue to second language writing to explore the influence of College Students' mother tongue ability on second language writing level. They believed that Chinese proficiency variables could affect learners' English writing ability through direct or indirect paths, and English proficiency would play a restrictive role in the process of transfer. Chen Jiajia (2012) made an empirical study on the transfer of mother tongue and related teaching strategies in senior high school English writing. Combined with dislocation analysis theory, interlanguage theory, markedness theory and questionnaire survey, she found that high school students' English writing was mainly composed of intralingual errors and interlingual errors, and put forward corresponding teaching strategies such as comprehensible input strategies to help students improve their writing level.

\section{RESEARCH DESIGN}

Based on the theory of mother tongue transfer, this study includes two senior high school English writing tests and a questionnaire survey. It makes a correlation analysis of the students' compositions in the two monthly examinations and the changes of students' writing level before and after the experiment.

\section{A. Research Questions}

There are research questions: 1. What errors in second language writing can be caused by native language transfer? 2 . Is there a significant correlation between L1 transfer and English writing proficiency? 3. In senior high school English writing teaching, is it effective to adopt teaching methods related to native language transfer to improve students' English writing level?

\section{B. Subjects of Research}

In this study, two classes of senior high school students in Henan Province were selected as the research objects, including 69 students in class 1 and class 2 respectively, selecting class 1 as experimental class and class 2 as control class. Considering that senior two students in high school have a certain foundation of English learning, and the pressure of entering school is moderate, in addition, the two classes are taught by the same English teacher, and the ratio of male and female is basically balanced, which greatly improves the reliability and validity of the study.

\section{Research Methods and Instruments}

This study focuses on the phenomenon of L1 transfer in senior high school students' English writing. Using the method of questionnaire survey, this article selects the questionnaire and two English compositions of senior two students as the corpus. The author distributes 162 questionnaires to the students in two classes to investigate the use of mother tongue in English writing. Considering the actual English learning situation of senior high school students, it doesn't involve too many professional terms. The topics of the two compositions are as follows:

Topic 1: please describe a person who is deeply impressed in your life and give examples of them.

Topic 2: the school holds a composition competition. Write an essay about the person you love or respect.

\section{Procedures of the Research}

(1) In the face of 138 students in two classes of senior two, the questionnaire on mother tongue transfer was issued and the data were statistically analyzed to understand the situation of senior two students' understanding of mother tongue transfer, master the overall situation of students and prepare for the next research adjustment.

(2) At First, the composition test was held, and a pretest was conducted for this two classes. Two classes taught by the 
same teacher are selected. A pretest was conducted to test whether the students in the two classes had the same level.

(3) Combined with the theory of mother tongue transfer, the corresponding teaching methods are carried out in the experimental class, involving words, phrases, sentences and other aspects of mother tongue transfer. When teaching, pay attention to the use of interlanguage related knowledge to help students understand English and try to use more comprehensible input. In the control class, the traditional writing teaching mode remains unchanged.

(4) Four weeks later, the students in the experimental class and the control class were tested again. Analyze the composition samples in the post test. Categorize the errors and deal with the scores of the two classes

(5) Compare the scores of the two compositions and relevant data.

\section{DATA ANALYSIS AND DiSCUSSION}

A total of 162 questionnaires were distributed to the two classes, of which 156 were valid. The recovery rate of the questionnaires reached the research standard. The main purpose of this study was to investigate whether high school students were affected by mother tongue transfer in their English writing. The tables are as follows:

TABLE 1

A SURVEY OF NATIVE LANGUAGE TRANSFER IN ENGLISH WRITING

\begin{tabular}{|c|c|c|c|c|c|}
\hline & Always & Often & Sometimes & Seldom & Never \\
\hline $\begin{array}{l}1 \text { Before writing an English composition, think about } \\
\text { Chinese in your mind. }\end{array}$ & $55 \%$ & $25 \%$ & $13 \%$ & $4 \%$ & $3 \%$ \\
\hline $\begin{array}{l}2 \text { When writing English composition, adopt Chinese } \\
\text { writing style and format. }\end{array}$ & $17 \%$ & $34 \%$ & $27 \%$ & $15 \%$ & $8 \%$ \\
\hline 3 Like using simple sentences in English composition. & $18 \%$ & $48 \%$ & $23 \%$ & $10 \%$ & $1 \%$ \\
\hline $\begin{array}{l}4 \text { After writing the English composition, translate it } \\
\text { into Chinese to see if it conforms to the content. }\end{array}$ & $19 \%$ & $19 \%$ & $19 \%$ & $27 \%$ & $18 \%$ \\
\hline $\begin{array}{l}5 \text { When writing English composition, avoid } \\
\text { subjunctive mood and independent structure. }\end{array}$ & $27 \%$ & $27 \%$ & $27 \%$ & $9 \%$ & $10 \%$ \\
\hline $\begin{array}{l}6 \text { Like using complex sentences in English } \\
\text { composition. }\end{array}$ & $9 \%$ & $15 \%$ & $33 \%$ & $30 \%$ & $13 \%$ \\
\hline $\begin{array}{l}\text { 7When writing English sentences, first write the } \\
\text { modifier, then write the head word. }\end{array}$ & $3 \%$ & $14 \%$ & $32 \%$ & $31 \%$ & $19 \%$ \\
\hline $\begin{array}{l}\text { 8Before writing English sentences, check the sentence } \\
\text { structure in your mind to see if it is grammatical. }\end{array}$ & $14 \%$ & $28 \%$ & $24 \%$ & $23 \%$ & $11 \%$ \\
\hline 9Having the habit of writing English diary. & $5 \%$ & $6 \%$ & $6 \%$ & $17 \%$ & $65 \%$ \\
\hline 10Cultural barriers in English Writing. & $18 \%$ & $19 \%$ & $31 \%$ & $17 \%$ & $15 \%$ \\
\hline
\end{tabular}

Through the investigation, we found that more than half of the students rely on a variety of Chinese thinking or writing methods in their English compositions. When writing English composition, only $23 \%$ of the students seldom or never adopt Chinese writing style and format. Before and after English writing, there are quite a number of people thinking about Chinese in mind or through translating into Chinese to check the composition, only $3 \%$ of the students never consider Chinese before writing and $18 \%$ of the students don't think about Chinese translation after composition at all. These phenomena surely reflect that senior high school students will be imperceptibly influenced and relied by Chinese thinking when they write English composition. Besides, $81 \%$ of the students will deliberately avoid the subjunctive mood and independent structure, which is enough to show the great influence of Chinese thinking mode on Chinese senior high school students' English writing. Therefore, according to the above table, we can draw a conclusion that senior high school students' English writing will be influenced by their mother tongue transfer greatly.

Then, what are the language errors caused by mother tongue transfer? And why the phenomenon of negative transfer of mother tongue occurs? Since Chinese belongs to the Sino-Tibetan system and there is no morphological change of strict meaning in Chinese expression, while English belongs to the India-European system, there are bound to be many different ways of expressions and structures between the two languages. In addition, lacking in language environment is also an important reason why students can not actively use the positive transfer of their mother tongue to learn a second language. This also makes students' second language awareness weak, prone to use errors, which is an inevitable phenomenon. Different teaching strategies also affect the acquisition of second language knowledge and the occurrence and intensity of transfer. Therefore, it is very important to strengthen the cultivation of students' language awareness and sense in second language teaching. Referring to James's classification of interlanguage(1980), it is divided into interlingual errors and intralingual errors. 
TABLE 2

INTERLINGUAL ERRORS IN SAMPLES

\begin{tabular}{|l|l|l|l|l|}
\hline Error performance & $\begin{array}{l}\text { Frequency of occurrence in } \\
\text { Topic 1 }\end{array}$ & $\begin{array}{l}\text { Frequency of occurrence in } \\
\text { Topic 2 }\end{array}$ & Total & Proportion \\
\hline Spelling mistakes & 50 & 23 & 73 & $5 \%$ \\
\hline Punctuation error & 25 & 19 & 44 & $3 \%$ \\
\hline Singular and plural errors & 81 & 42 & 123 & $9 \%$ \\
\hline Wrong use of articles & 35 & 16 & 51 & $4 \%$ \\
\hline Pronoun errors & 43 & 35 & 78 & $6 \%$ \\
\hline Wrong use of adjectives & 40 & 35 & 75 & $5 \%$ \\
\hline Preposition error & 25 & 19 & 44 & $3 \%$ \\
\hline Consistency error & 95 & 61 & 156 & $11 \%$ \\
\hline Part of speech confusion & 43 & 33 & 77 & $6 \%$ \\
\hline Incorrect use of phrases & 65 & 70 & 135 & $10 \%$ \\
\hline Wrong use of conjunctions & 52 & 27 & 79 & $6 \%$ \\
\hline Wrong use of passive voice & 63 & 84 & 147 & $11 \%$ \\
\hline Tense error & 90 & 67 & 157 & $11 \%$ \\
\hline $\begin{array}{l}\text { Wrong use of sentence } \\
\text { patterns }\end{array}$ & 46 & 32 & 78 & $6 \%$ \\
\hline Chinglish & 35 & 14 & 49 & $4 \%$ \\
\hline
\end{tabular}

TABLE 3

INTRALINGUAL ERRORS IN SAMPLES

\begin{tabular}{|l|l|l|l|l|}
\hline Error performance & $\begin{array}{l}\text { Frequency of occurrence in } \\
\text { Topic 1 }\end{array}$ & $\begin{array}{l}\text { Frequency of occurrence in } \\
\text { Topic 2 }\end{array}$ & Total & Proportion \\
\hline Spelling mistakes & 56 & 42 & 98 & $8 \%$ \\
\hline Punctuation error & 23 & 19 & 42 & $4 \%$ \\
\hline Singular and plural errors & 65 & 41 & 106 & $9 \%$ \\
\hline Wrong use of articles & 33 & 30 & 63 & $5 \%$ \\
\hline Pronoun errors & 21 & 20 & 41 & $4 \%$ \\
\hline Wrong use of adjectives & 45 & 32 & 77 & $6 \%$ \\
\hline Preposition error & 18 & 7 & 25 & $2 \%$ \\
\hline Consistency error & 83 & 58 & 141 & $12 \%$ \\
\hline Part of speech confusion & 41 & 32 & 73 & $6 \%$ \\
\hline Incorrect use of phrases & 38 & 23 & 61 & $5 \%$ \\
\hline Wrong use of conjunctions & 39 & 30 & 69 & $6 \%$ \\
\hline Wrong use of passive voice & 52 & 49 & 101 & $9 \%$ \\
\hline Tense error & 65 & 55 & 120 & $10 \%$ \\
\hline $\begin{array}{l}\text { Wrong use of sentence } \\
\text { patterns }\end{array}$ & 43 & 38 & 81 & $7 \%$ \\
\hline Other errors & 33 & 39 & 72 & $7 \%$ \\
\hline
\end{tabular}

\section{(1) Punctuation error}

Although we quarreled sometimes we still have a good relationship. (Topic 1)

The punctuation of the sentence is missing, beginning with "empty", and a comma is missing between "sometimes" and "we". This is against the rules of English sentences.

(2) Singular and plural errors

He has a nice features, because many people admire him. (Topic 1)

In this sentence, the use of the singular and plural is wrong, which leads to the confusion of inconsistency.

Although both English and Chinese have singular and plural expressions, their expressions are quite different, which makes Chinese students unable to take care of them. In English, the plural number is usually represented by suffixes, while in Chinese it is expressed by the preceding articles, while the Chinese characters themselves are not changed.

(3) Tense error

One day, he told me that he wants to invent a car that won't pollute the environment.(Topic 1)

In English, tense changes are not only reflected in time adverbs, but also in verbs. While in Chinese, Tenses are usually presented by temporal words, and there is no change in action words. This difference can also easily lead to syntactic errors in English composition and produce negative transfer of mother tongue.

(4) Part of speech confusion

I have become his proud from now on. (Topic 1)

"Proud" belongs to adjectives, we should use noun "praise" here. In Chinese, the same word contains different parts of speech, which can be perceived through the context, and does not need to be displayed by the word itself. In English, the words themselves will change or be displayed by different words. Because the target language is not proficient, it is easy to confuse parts of speech in English writing.

(5) Consistency error

She often tell me never giver up.(Topic 1)

Every time I have some problems in learning English, she can always answer my questions as soon as possible. (Topic 2) 
Through the observation of the sample, the consistent errors are usually manifested in the inconsistent subject predicate and verb object collocation.

In order to further explore whether mother tongue transfer has a real impact on students' second language writing learning, we make the following analysis.

TABLE 4

GROUP STATISTICS

\begin{tabular}{|l|l|l|l|l|l|l|l|}
\hline \multirow{2}{*}{ Classes } & \multirow{2}{*}{ Number } & \multicolumn{2}{|l|}{ Average value } & Standard deviation & \multicolumn{2}{l|}{ Standard error mean } \\
\cline { 3 - 8 } & & pretest & Post-test & pretest & Post-test & pretest & Post-test \\
\hline experimental class & 69 & 19.23 & 20.10 & 1.82 & 1.60 & 0.22 & 0.2 \\
\hline control class & 69 & 19.29 & 19.55 & 1.55 & 1.64 & 0.19 & 0.2 \\
\hline
\end{tabular}

TABLE 5

INDEPENDENT SAMPLES TEST

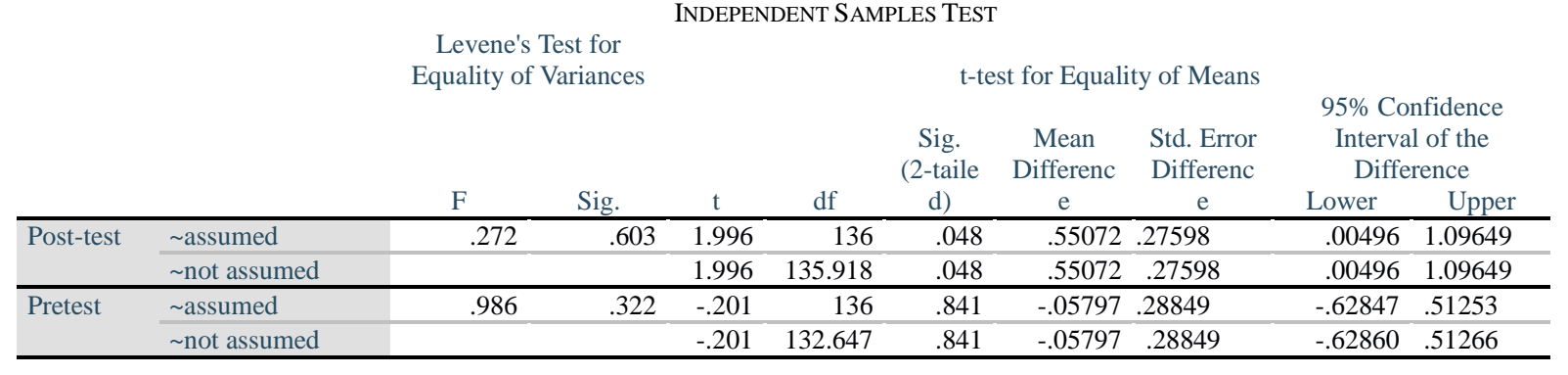

There are 69 samples in the experimental class and control class respectively. Through the experiment, it is found that there is a certain gap between the average scores of the control class and the experimental class in the pretest and post-test. From the pretest table, the average score of the pretest of the experimental class is 19.23, while the control class is 19.28. About the standard deviation of the pretest, one is 1.82 and another is 1.55 . Besides, according to the statistics that $\mathrm{p}>0.05$ in pretest $\mathrm{t}$-test output we draw the conclusion that there is no significant difference in English writing between the two classes before the experiment and the two classes are in the same level.

After four weeks of mother tongue transfer teaching experiment in the experimental class, the control class still uses traditional teaching mode. An independent-samples t-test was run to determine if there were differences in English writing scores between students getting new teaching mode or not. It can be found that there is a statistically significant difference of $0.55(95 \% \mathrm{CI}, 0.05$ to 1.1$), \mathrm{t}(135)=1.996, \mathrm{p}<0.05$, so there is a significant difference in two classes' English writing grades, which represents native language teaching method and traditional teaching method respectively. Therefore it can conclude that native language transfer can have an influence on English writing level and proper use of native language transfer teaching can help students improve their English level, especially adopts the comprehensible input method. After the experimental verification, these data have reliability and authenticity, this study is worthy of trust and value.

\section{Enlightenment of NATive-language Transfer on Senior High School English Writing Teaching}

Native language transfer has always been a hot topic in psychology and linguistics. It can be said that it has an inevitable impact on second language learning. Therefore, we must have a correct understanding of mother tongue transfer, recognize its cognitive rules, and reasonably use its positive influence in order to make our second language level to a higher level. In the teaching process, teachers should fully grasp the law of transfer, deeply understand the mode of second language learning, and give full play to the positive role of mother tongue transfer to guide students' learning.

\section{A. Try to Reduce the Negative Transfer of Native Language to English Writing}

Combined with the previous representation of the negative transfer of mother tongue which easily leads to second language errors, teachers should be brave to adopt a new model in the teaching process, and carry out targeted teaching and training for the places where transfer is easy to lead to language errors. Only by strengthening the students' extensive reading ability and accumulating a large amount of reading and the input of second language thinking mode can students master certain cultural accumulation. At the same time, students should be trained to think in English rather than in their native language mind. In addition, targeted training and guidance should be carried out to help students avoid such errors. It's very important to pay attention to the mode of comprehensible input. Teachers can train students through various forms of English materials and learning forms, cultivate students' sense of language, and elaborate the content, so that students can have good second language ideas when using second language and inhibit the negative transfer of mother tongue. Teachers should correct students' language errors in time to prevent negative language transfer.

\section{B. Employing Positive Transfer of Native Language to Improve Second Language Writing}

Although there are differences between different cultures, there are also common points for reference. There is a 
regular relationship between many English words and Chinese words. Teachers can use positive transfer to guide students to improve their vocabulary and syntactic knowledge, so as to lay a foundation for improving their writing ability. Before teaching a second language in class, teachers should lead students to compare the differences between English and Chinese, and create context to cultivate students' English thinking and language mastery ability. In order to improve the level of second language writing, we should guide students to overcome Chinese thinking patterns, create new second language thinking, understand and internalize the second language. Besides, teachers should urge students to form good behavior habits, standardize the writing modes and carry out diversified writing training.

\section{CONCLUSION}

English writing is one of the important ways to show the comprehensive ability of English. It is of great significance to improve the English writing scores of high school students. The transfer of native language can lead to high school students' English writing errors, and it accounts for a large proportion, which should be paid attention to. In addition, through the experiment, it is found that native language has a significant difference on students' English writing level. For this reason, teachers can adopt appropriate teaching strategies, such as the transmission of comprehensible input, to help guide senior high school students to correctly use native transfer so as to improve their writing level. Of course, this study is not rigorous enough, the specific role and implementation of mother tongue transfer are not deep enough, and it needs to be further improved near the future.

\section{REFERENCES}

[1] Chang, C. \& Chang, H.C. (2020). Retrospect and Prospect of EFL Writing Research in China. Audio visual foreign language teaching, 3, 61-67.

[2] Chen, J. J. (2012). An Empirical Study of Mother Tongue Transfer and Relevant Teaching Strategies in Senior High School English Writing. Shandong Normal University.

[3] Dai, W. D. (2002). Language Transfer Studies: Issues and Reflections. Foreign Language, 6, 1—9.

[4] Halliday, M.A.K. \& R. Hasan. (1985). Context and Text: Aspect of Language in a Social -Semiotic Perspective. Victoria: Deakin University Press.

[5] James, C. (1980). Contrastive Analysis. New York: Longman Inc.

[6] Krashen, Stephen \& Tracy Terrrell. (1983). The Nature Approach. Oxford: Pergamon/Alemany Press.

[7] Lay, N. D. S. (1982). Composing processes of adult ESL learners: a case study. TESOL Quarterly, 16, 406-107.

[8] Odlin, T. (1989). Language Transfer: Cross-linguistic influence in language learning. Cambridge: Cambridge University Press.

[9] Wang, L. F. \& Wen, Q. F. (2004). The Transfer of Mother Tongue Level to Second Language Writing: Cross Language Motivation and Path. Foreign language teaching and research, 3, 205-211.

[10] Wang, W.Y. \& Wang, L.F. (2004). A review and Prospect of second language writing in the past decade. Foreign language circles, 3, 51-28.

Yuhang Yuan was born in Henan, China in 1997. She received her bachelor's degree from Hunan, China in 2019.

She is currently a second year graduate student majoring in linguistics in University of Shanghai for Science and Technology. Her research interests include Cognitive neurolinguistics and Pragmatics. 